\title{
Tissue reaction after intrastromal corneal ring implantation in an experimental animal model
}

\author{
Lucía Ibares-Frías • Patricia Gallego • Roberto Cantalapiedra-Rodríguez • \\ María Cruz Valsero • Santiago Mar • Jesús Merayo-Lloves • \\ María Carmen Martínez-García
}

Received: 19 October 2014 / Revised: 22 January 2015 / Accepted: 27 January 2015 / Published online: 7 March 2015

(C) Springer-Verlag Berlin Heidelberg 2015

\begin{abstract}
Purpose To evaluate corneal wound healing in the hen animal model after additive surgery with an intracorneal ring segment (ICRS).

Methods We implanted one ICRS in each eye of 76 hens. In control group 1 ( $\mathrm{n}=22$ hens), the stromal channel was prepared but no ICRS was inserted. In control group $2(\mathrm{n}=2$ hens), no surgery was performed. Animals were randomly separated into groups and euthanized after clinical follow-up of 4 and 12 hours, 1, 2, 3, and 7 days, and 1, 2, 3, 4, and 6 months. Corneas were stained with hematoxylin-eosin. Apoptosis was measured by terminal uridine nick end-labeling assays. Cell proliferation and myofibroblast-like differentiation were assayed by BrdU and $\alpha$-smooth muscle actin immunofluorescence microscopy. Stromal matrix changes were documented by electron microscopy.
\end{abstract}

Data in this manuscript were presented in part at the 2014 Association for Research in Vision and Ophthalmology (ARVO) Annual Meeting, May 4-8, 2014, in Orlando, FL, USA. This work was supported by Grant FISPI: PIO52841; Profit cit-300100-2007-50.

Electronic supplementary material The online version of this article (doi:10.1007/s00417-015-2959-5) contains supplementary material available to authorized users.

L. Ibares-Frías · P. Gallego • M. C. Valsero · S. Mar •

J. Merayo-Lloves $\cdot$ M. C. Martínez-García

Group of Optical Diagnostic Techniques, Theorist, Atomic and

Optical Physics Department, Faculty of Science, University of

Valladolid, Valladolid, Spain

L. Ibares-Frías $\cdot \mathrm{S}$. Mar

Institute of Applied Ophthalmobiology (IOBA), University of

Valladolid, Valladolid, Spain

L. Ibares-Frías $(\bowtie)$

Ophthalmology Department, Hospital Clínico Universitario de

Valladolid, Valladolid, Spain

e-mail: luciaibares@hotmail.com
Results Epithelial and stromal cell apoptosis around the ICRS-implanted and control group 1 eyes peaked at 12 hours, but continued for 72 hours. In ICRSimplanted eyes, epithelial and stromal proliferation was present at 12 and 24 hours, respectively, and peaked at 7 days and 72 hours, respectively. Some proliferation in the ICRS-implanted group continued through the 6month follow-up, and myofibroblast-like cells differentiated one to three months after ICRS implantation. The segments rotated within the stroma as the limbal inferior angle approached the epithelium.

Conclusions Wound healing after ICRS implantation in hen corneas was similar to that of other corneal surgical wounds in stages. However, there were some specific features related to the small size of the epithelial wound and the device permanently implanted inside the cornea.

P. Gallego • R. Cantalapiedra-Rodríguez • M. C. Martínez-García Cellular Biology, Histology and Pharmacology Department, Faculty of Medicine, University of Valladolid, Valladolid, Spain

M. C. Valsero

Biostatistics Department, Faculty of Science, University of Valladolid, Valladolid, Spain

J. Merayo-Lloves

Fundación de Investigación Oftalmológica, Instituto Oftalmológico

Fernandez Vega, Oviedo, Spain 
Keywords Experimental animal model · Additive surgery . Intrastromal corneal ring segments $\cdot$ Wound healing $\cdot$ Stroma . Keratoconus

\section{Introduction}

Keratoconus, pellucid marginal degeneration, and laserassisted in-situ keratomileusis (LASIK) secondary ectasia are classically described as a group of diseases characterized by progressive corneal thinning with an irregular increase in the corneal refractive power without evidence of clinical inflammation $[1,2]$. In the past, keratoplasty was the only option for mitigating these disorders after contact lens fitting [2, 3], but there are now several options, such as cross-linking [4] and implantation of an intrastromal corneal ring segment (ICRS) [5].

Since 1999, when the U.S. Food and Drug Administration approved ICRS-INTACS ${ }^{\mathrm{TM}}[6,7]$, many people worldwide have undergone ICRS implantation [8,9], not only for myopia but also as an orthopedic procedure for ectatic diseases. ICRS surgery has some advantages over other keratorefractive techniques. For instance, it does not involve any surgical incursion of the central cornea; thus, the normal physiologically prolate corneal profile is maintained with concomitant reduction of the central corneal curvature. Further, the refractive effect is potentially reversible [10].

Despite the many studies on ICRS implantation carried out by clinical examinations, confocal microscopy [11], optical coherence tomography (OCT) [12-15], and electron microscopy $[16,17]$, there are insufficient data regarding the wound healing process associated with the procedure. Understanding this process could contribute to the safety and efficacy of refractive surgical procedures, and it may also permit the development of methods for avoiding complications that can arise. Most of the histological studies after ICRS implantation have been carried out in human corneal tissue after complications or when the cornea was removed for keratoplasty [18-21]. Histopathological studies in animals have been performed in rabbits [17] and hens [22]. However, there are relatively few studies that have reported the complete histological changes that occur during the wound healing process of both human and animal corneas [17, 18, 20,21]. These studies included only a small number of eyes and did not show the evolution of the process over a sufficient amount of time, especially soon after surgery, to document all of the changes that take place.

Wound healing after photorefractive keratectomy (PRK) and LASIK surgery has been described as a cascade of events, regulated by several cytokines and growth factors synthesized and released by the epithelium and lacrimal gland [23-25]. The quiescent keratocytes around the wound are stimulated to either undergo cell death, or alternatively, to lose the quiescent state and transition into repair or "activated" phenotypes. These activated cells have properties of fibroblasts and myofibroblasts that develop $\alpha$-smooth muscle actin stress fibers. Both cells aid in the regeneration of a normal stromal matrix. These repair phenotypes are dependent on specific environmental signals such as growth factors. Later, they undergo apoptosis, and the keratocytes repopulate the wound area. Thus, the aim of the present study was to describe the wound healing process from four hours to six months after ICRS implantation in the hen animal model, and to correlate it with the clinical events observed in vivo.

\section{Materials and methods}

Animals

Iber Braun adult hens $(\mathrm{n}=100)$, Gallus gallus domesticus, weighing about $2.5 \mathrm{~kg}$ each, were cared for following the guidelines of the Association for Research in Vision and Ophthalmology (ARVO) Statement for the Use of Animals in Ophthalmic and Vision Research. Care oversight of animals used for scientific purposes in the University of Valladolid was provided by the Ethics and Animal Welfare Committee.

The hens were randomly divided into three groups: ICRS implantation ( $\mathrm{n}=76$ hens, both eyes); control group 1 in which the intrastromal channel was made but the ICRS was not implanted ( $\mathrm{n}=22$ hens, both eyes); and control group 2 in which there was no surgery ( $n=2$ hens). For surgery, the hens were anaesthetized with an intramuscular injection of ketamine hydrochloride (37.5 mg/kg; Ketolar, Parke Davis SA, Barcelona, Spain) and xylazine hydrochloride (5 mg/kg; Rompun, Bayer, Leverkusen, Germany) followed by topical application of $0.5 \%$ tetracaine hydrochloride and $1 \mathrm{mg}$ of oxybuprocaine (Colircusi Anestésico Doble, Alconcusí SA, Barcelona, Spain).

\section{ICRS implantation}

One Ferrara Ring ${ }^{\circledR}$ segment (AJL Ophthalmics, Vitoria, Spain), made of polymethyl methacrylate (PMMA), was implanted in each eye (Video 1). Each segment was triangular in cross-section with a thickness of $0.15 \mathrm{~mm}$, a base of $0.6 \mathrm{~mm}$, an arc length of $90^{\circ}$, an inner diameter of $4.4 \mathrm{~mm}$, and an outer diameter of $5.6 \mathrm{~mm}$. Briefly, using an adjustable Ferrara diamond blade knife, an incision was made through $70-80 \%$ of the corneal thickness at the 6 o'clock position, between 5 and $7 \mathrm{~mm}$ from the center of the cornea. A corneal bag was then made using a Suarez Spreader to facilitate the beginning of the channel preparation. A Ferrara spatula, modified for the chicken cornea (5-mm diameter) was inserted into the bag to create a circular channel where the PMMA segments were then implanted. The segments were inserted to maintain a distance of 
$1 \mathrm{~mm}$ from the incision. In control group 1, the tunnel was made, but no segment was implanted.

\section{Clinical course}

The corneas were evaluated under a surgical microscope (Leica M220 F12, Leica Microsystems, Nussloch, Germany) before and after ICRS implantation. The animals were observed at 24, 48, 72 hours, 7 and 15 days, and monthly for up to 6 months. Epithelial wound closure was measured by sodium fluorescein staining (Fluotest ${ }^{\circledR}$, Alcon, Cusi, Barcelona) every eight hours until epithelial closure was complete. Corneal edema was measured in the central cornea, the incision, and the channel around the segment, and channels without a segment according to the Efron scale for stromal edema [26]. Deposits that developed in association with the segments were graded on the Ruckhofer scale [18]. Haze was also graded on a 1-4 scale according to Fantes [27].

Tissue processing and light microscopy

Animals were euthanized by an intracardiac injection of sodium pentobarbital (Dolethal ${ }^{\circledR}$ 0737-ESP Vetoquinol, Madrid, Spain) while under general anesthesia. Eleven time points after ICRS implantation or after channel preparation in control group 1 were examined histologically at 4, 12, 24, 48, and 72 hours, 7 days, and 1, 2, 3, 4 and 6 months. These times were chosen based on previous wound healing studies in hens and rabbits $[17,22,23]$. Enucleated eyes were fixed with $10 \%$ buffered formalin and embedded in paraffin. Sections $7-\mu \mathrm{m}$ thick were stained with hematoxylin-eosin (H-E). The sections were examined under an Olympus BX41 microscope

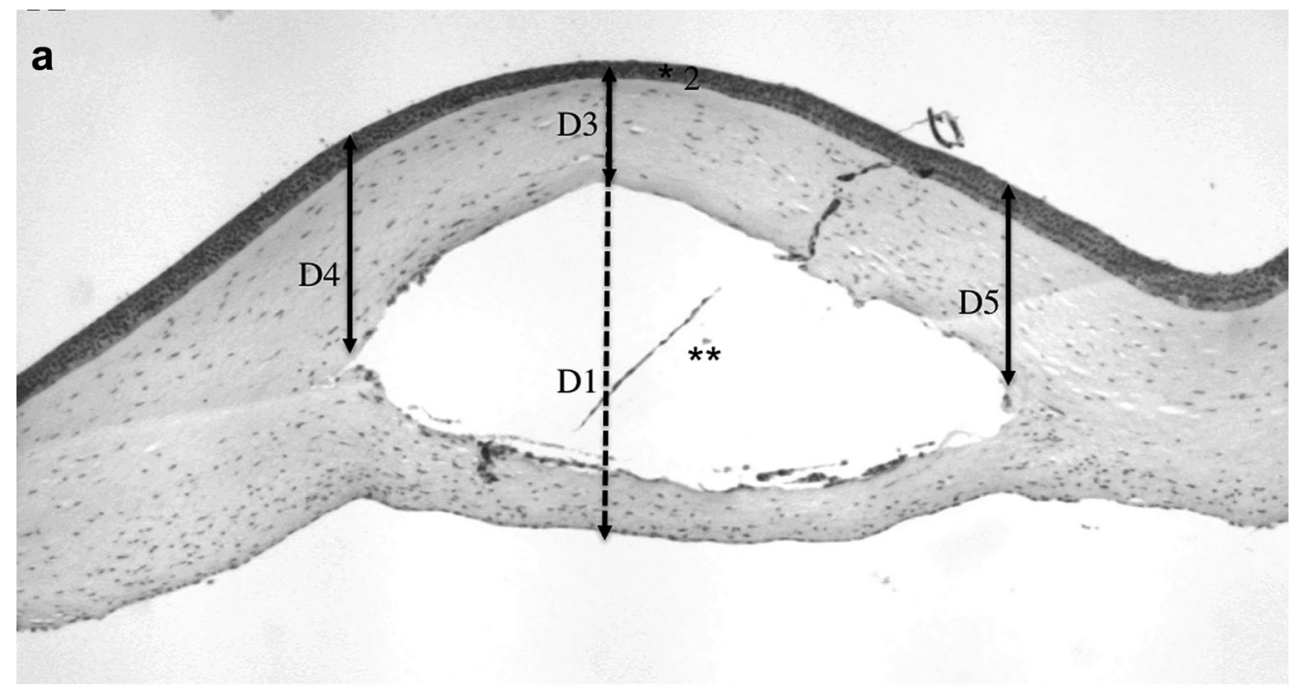

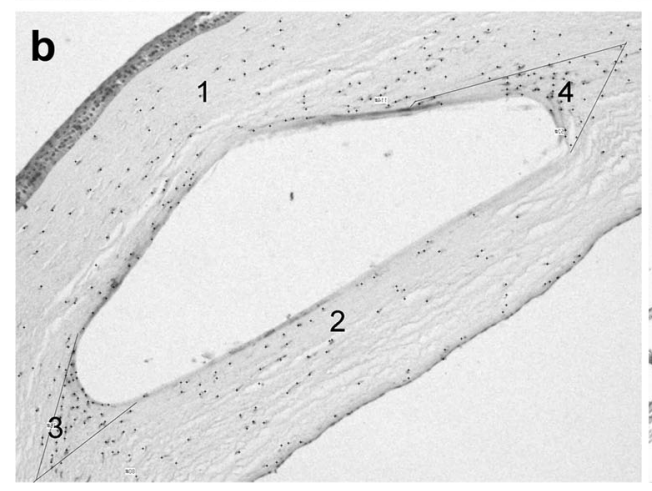

Fig. 1 (a) Distances (D) measured from $4 \times$ hematoxylin-eosin-stained micrographs in the area where the ICRS was implanted. The following distances at the site of implantation were measured: D1, corneal thickness in the area of the segment; *2, epithelial thickness; D3, distance between the epithelium and the peak of the hole left after the segment was lost during processing; D4, distance between the epithelium and the outer inferior angle of the hole left by the segment (limbus side); D5, distance between the epithelium and the inner inferior angle of the hole left by the segment (Center side); **, Perimeter of the triangular hole left by the

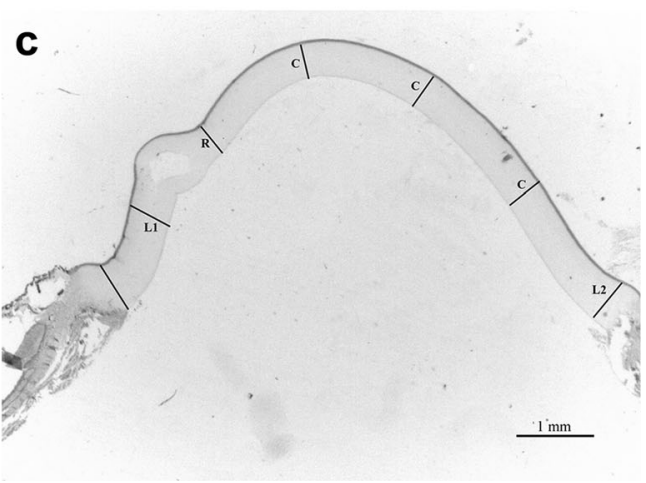

ICRS. (b) Cells around the ICRS were counted in different areas of the H-E-stained corneas: Area 1, the area above the segment location; Area 2, the area below the segment location; Area 3, triangular area around the inferior angle of the hole left by the segment near the limbus; Area 4, the opposite triangular area around the inferior angle of the hole left by the segment near the center of the cornea; 10× magnification. (c) BrdUpositive cells were counted in the following areas: L1, limbus near the segment; $\mathrm{R}$, area containing the segment; $\mathrm{C}$, three equal areas of central cornea; L2, limbus far from the segment 
(Olympus Life Science, Hamburg, Germany) and photomicrographs were obtained with an Olympus DP20 digital camera. Quantitative measurements of the photographs were taken using the program Cell A (Olympus Soft Imaging Solutions $\mathrm{GmbH}$, Münster, Germany). Distances between the upper, inner, and outer edges of the implanted segment site and the corneal epithelium were measured in two images of each cornea at $4 \times$ magnification (Fig. 1a). Stromal cells were counted at $10 \times$ magnification using the touch count function in a total area of $371,162 \mu \mathrm{m}^{2}$ near the ICRS. The counts were made in four different areas of the image where the cells were aggregated (Fig. 1b).

To avoid measurement artifacts in the sections, we standardized the histological procedures. All of the H-E preparations were made by the same experienced technician, with the same concentrations of reagents, time interval between steps (tissue harvesting and fixation, fixation and embedding), section thickness, and post-fixation storage conditions.

Either 12 or 13 corneas in the ICRS-implanted group were examined at each of the eleven time points. In control group 1, four corneas at each of the eleven time points were examined. In control group 2, only four corneas were examined.

\section{Cell death}

To detect DNA fragmentation associated with apoptosis, terminal uridine nick end-labelling (TUNEL) assays were performed in deparaffinized sections according to the manufacturer's instructions (TUNEL Ref: G3250, Promega Corp., Madison, WI, USA). Nuclei were counterstained with 4',6diamino-2 phenylindole (DAPI, D9542, Sigma-Aldrich, Munich, Germany).

\section{Cell proliferation}

One hour before euthanasia, all animals received an intramuscular injection of 5-bromo-2'-deoxyuridine (BrdU, Sigma-
Aldrich), a marker of DNA synthesis $(10 \mathrm{mg} / \mathrm{ml}, 5 \mathrm{ml} / \mathrm{kg})$. Paraffin-embedded sections were deparaffinized and treated with $2-\mathrm{N} \mathrm{HCl}$ for 1 hour and then incubated with mouse monoclonal IgG anti-BrdU (DakoCytomation, Carpinteria, CA, USA) for 30 minutes at room temperature. The secondary antibody was fluorescein goat anti-mouse IgG (1:100, Molecular Probes, Leiden, The Netherlands) in Tris-buffered saline. Control slides were prepared by omission of the primary antibody.

Using 20× magnification micrographs, epithelial and stromal BrdU-positive cells were counted in six equal areas (Fig. 1c): L1, limbus near the segment; R, area containing the segment; $\mathrm{C}$, three equal areas of the central cornea; and L2, limbus far from the segment. The number of BrdUpositive cells in the three areas of the central cornea (labeled $\mathrm{C}$ in Fig. 1c) were averaged and compared with the other three areas (labeled L1, R, and L2 in Fig. 1c).

\section{Differentiation of myofibroblast cells}

Myofibroblast- cells were identified by staining with anti- $\alpha$ SMA monoclonal antibody (mouse clone 1A4, DakoCytomation). The secondary antibody was Texas red goat anti-mouse IgG (Molecular Probes). Sections were examined under an Axiophot fluorescence-incorporated microscope (Zeiss Axiophot HB0-50, Carl Zeiss, Germany) and photomicrographs were captured using an AxioCam HRc digital camera and Axiovision release 4.8 software (Carl Zeiss). Limbal blood vessels served as positive controls, and omission of the primary antibody provided negative controls.

\section{Electron microscopy}

Ten corneas were taken for electron microscopy at postoperative months 1, 2, 3, 4 and 6 . They were fixed in $2 \%$ glutaraldehyde and $2 \%$ paraformaldehyde and post-fixed in $1 \%$ osmium tetroxide. The fixed tissues were embedded in Spurr's plastic. Selected sections were cut on a LKB
Fig. 2 Intrastromal deposits at one (a) and three months (b) along the inner curvature of the segment (arrows). During the first three months after ICRS insertion, the deposits remained stable in quantity, increased in severity, and changed from white to chalky. They were closer to the segment edge at three months
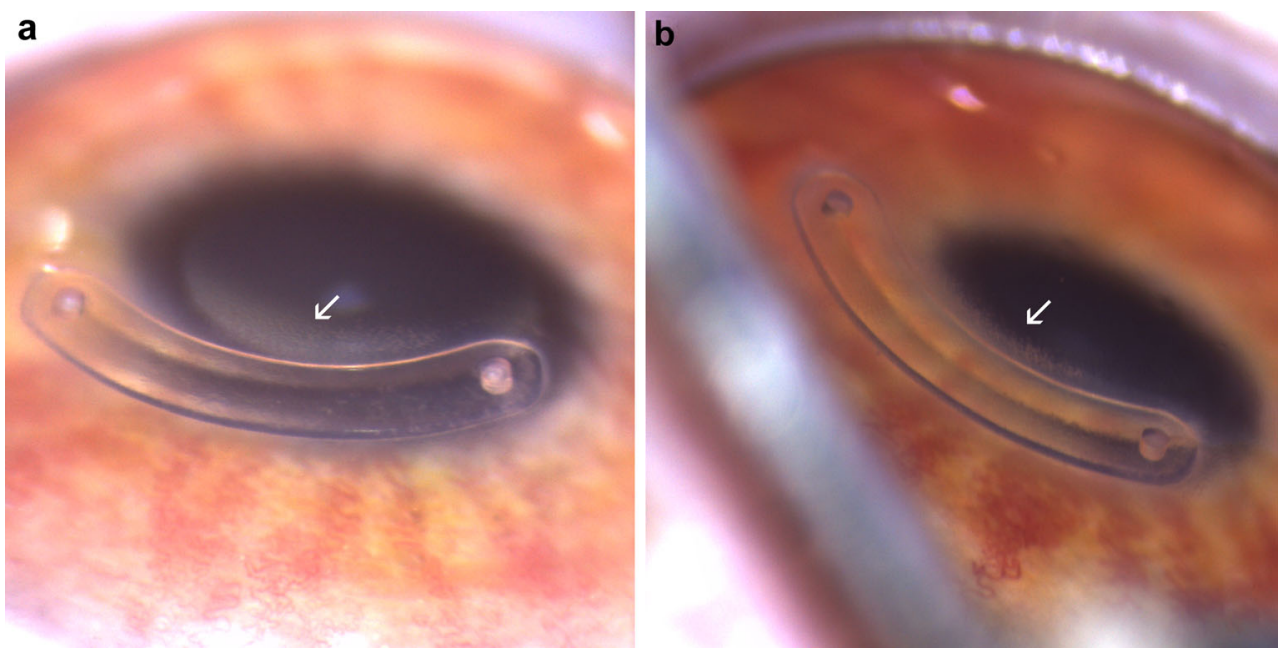

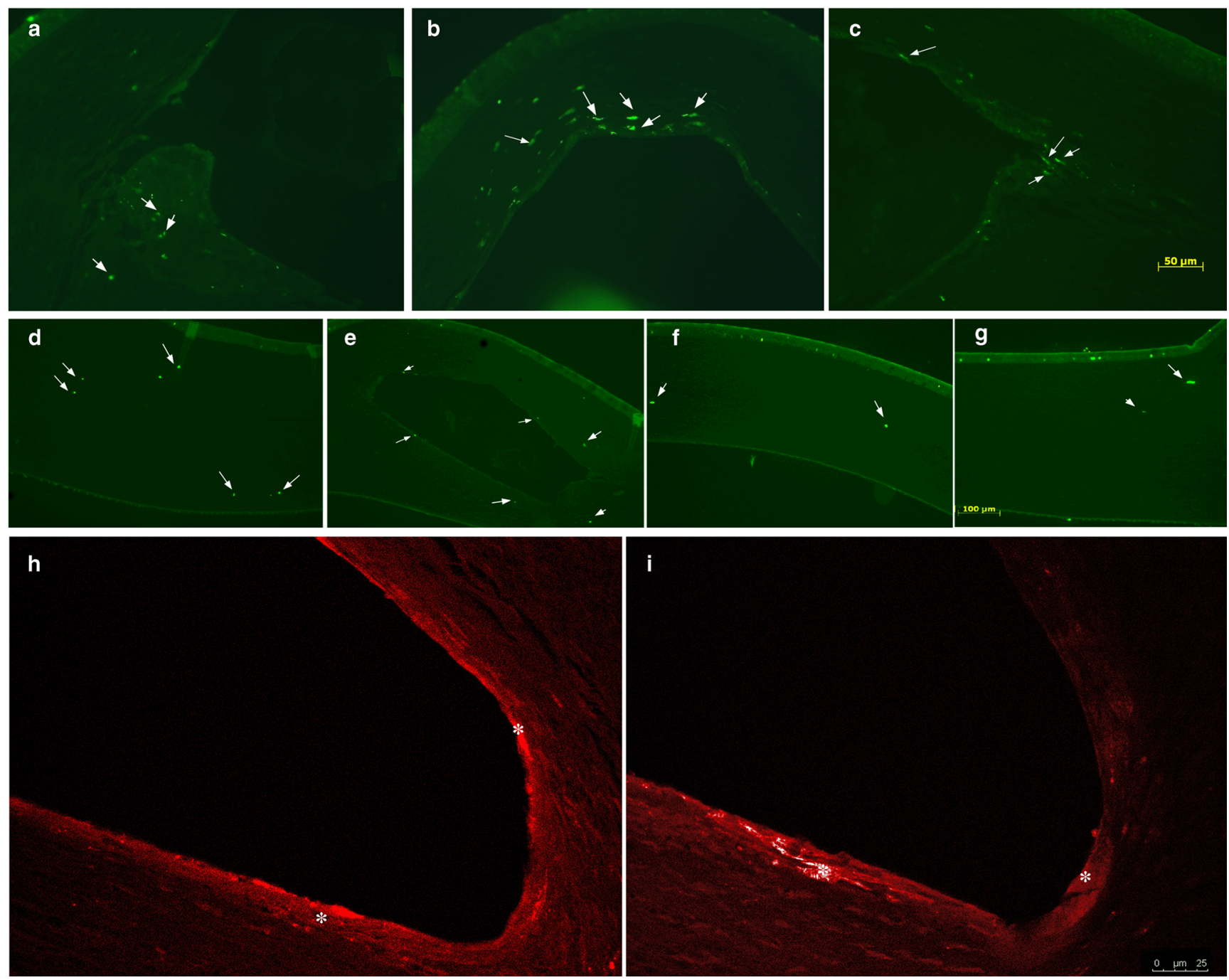

Fig. 3 Top row: TUNEL assay of the cornea for apoptotic cells at four hours after ICRS implantation. (a) Edge of the segment close to the limbus. (b) Between the segment and the epithelium. (c) Edge of the segment close to the center of the cornea. Middle row: Immunolocalization of epithelial and stromal BrdU-positive cells at 72 hours. Arrows: stromal-positive cells. (d) BrdU-positive cells in the epithelium and stroma at the limbus near the ICRS. (e) BrdU-positive

ultramicrotome (Prodkter AB, Stockholm, Sweden) and examined under a Jeol JEM-1200EXII electron microscope (Jeol Ltd., Tokyo, Japan).

\section{Statistical analysis}

Measured variables were analyzed by calculating the mean, standard deviation (SD), coefficient of variation, maximum and minimum values, asymmetry, and coefficient of kurtosis. After defining these parameters, variances were compared with the Levene test. If the variances were equal, an analysis of variance (ANOVA) table was used to test the equality of the means. If the variances were different, then the Kruskal-Wallis test was used to compare the equality of the medians.

cells in the epithelium and stroma around the ICRS. (f) BrdU-positive cells in one of the three areas of the central stroma. (g) BrdU-positive cells in the epithelium and stroma at the limbus far from the ICRS. There were no positive cells when the primary antibody was omitted. Bottom row: Immunolocalization of $\alpha$-SMA. (h) At one month, $\alpha$-SMA positive cells (*) were present in the inferior angle of the segment close to the center of the cornea. (i) A similar distribution was present at three months $\left({ }^{*}\right)$

Moreover, a multiple range test was used to determine which means were significantly different from others.

\section{Results}

\section{Clinical course}

At $3 \pm 2$ days after ICRS implantation, all of the epithelial wounds were closed. For all eyes, a slight corneal edema in the channel site was present during the first 7-15 days but was completely resolved by 1 month. Deposits appeared at seven days along the inner curvature of the segment. At one month, the quantity of deposits increased, and they were 
also located along the outer curvature and under the segment. The deposits were white in appearance and were not confluent (Fig. 2a). The severity increased until three months (grade 2-3) when they were more confluent, and they were located closer to the segment (Fig. 2b). At six months, the quantity of deposits decreased, and the severity also decreased to grade $1-2$. Corneal haze was present only at the incision site after closure of the wound in all the eyes in which surgery was performed.

\section{Cell death}

TUNEL-positive cells and cell debris were located in the superficial layer of the epithelium where apoptosis routinely occurs prior to sloughing off of the most apical cells. At four hours after ICRS implantation, positive cells were present in the deep stroma, scattered inside the empty channel used to insert the ICRS and around the segment (Fig. 3a, b, c). At 12 hours after implantation, the number of TUNEL-positive cells had decreased in all locations. At 24, 48, and 72 hours, only some of the corneas had TUNEL-positive cells around the segment. In control group 1, TUNEL-positive cells were present only at 4 and 12 hours after the channel was made. After 24 hours, only occasional TUNEL-positive cells were present.
In control group 2, only occasional TUNEL-positive cells were found in the superficial layer of epithelium at all times analyzed.

Cell proliferation

BrdU-positive cells, indicating cellular DNA synthesis, were detected in the epithelium as early as 12 hours after ICRS implantation. The peak appearance of positive cells in the epithelium was at seven days (Fig. 4a), principally over the superior vertex of the segment and in the central cornea where no segment was present. At one month, there were fewer BrdU-positive cells in the epithelium, and the decrease continued until two months. At four and six months, few BrdUpositive cells were detected in the epithelium, mostly over the central cornea (Fig. 4a).

BrdU-positive cells were present in the stroma as early as 24 hours after ICRS implantation. The peak number of stromal BrdU-positive cells was observed at 72 hours (Figs. 3d, e, f, g and $4 \mathrm{~b}$ ), located mainly in the adjoining limbus (Fig. 3d) and secondarily around the segment (Fig. 3e), the central cornea (Fig. 3f), and the other limbus (Fig. 3g). From 72 hours to 1 month, these cells were located principally around the segment, with the number decreasing over time. The mean
Fig. 4 Time-dependent changes in epithelial and stromal BrdUpositive cells after ICRS implantation. (a) Labeled epithelial cells were present 12 hours after ICRS implantation, and then diminished until peaking again at 7 days. BEC, BrdUpositive cells in the central epithelium; BER, BrdU-positive cells in the epithelium over the ICRS; BEL1, BrdU-positive cells in the epithelium at the limbus near the ICRS; BEL2, BrdUpositive cells in the epithelium at the limbus far from the ICRS. (b) Labeled stromal cells were present 24 hours after ICRS implantation and steadily increased until peaking at 72 hours. BSC, BrdU-positive cells in the central corneal stroma; BSR, BrdU-positive cells in the stroma around the ICRS; BSL1, BrdU-positive cells in the stroma at the limbus near the segment; BSL2, BrdU-positive cells in the stroma at the limbus far from the ICRS

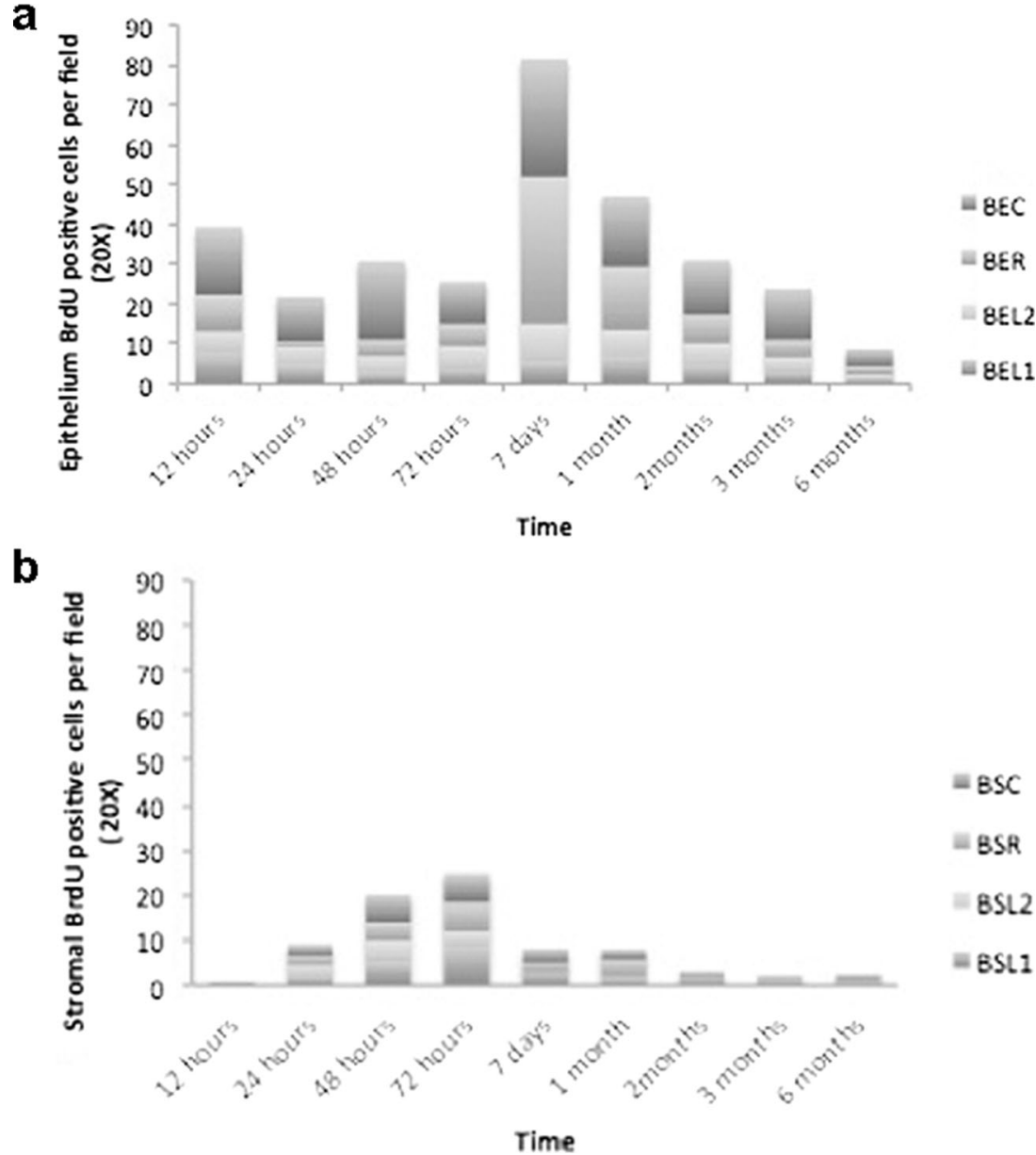


number of positive cells at 72 hours was significantly greater than at all later times $(p<0.01)$. At two months there were fewer BrdU-positive cells in the stroma. By four and six months post-implantation, labeled cells were only occasionally present.

For control group 1 in which no ICRS was inserted, BrdUpositive cells were present from 24 to 72 hours after the channel was made. They were present only in the basal layer of the epithelium and in the deep stroma near the channel. A few BrdUpositive cells were present in the basal layer of the epithelium of control group 2, and there were none present in the stroma.

\section{Differentiation of $\alpha$-SMA-positive cells}

$\alpha$-SMA-positive cells, indicating differentiation of myofibroblast cells, were detected only around the segment from one to three months after ICRS implantation (Fig. 3h and i). These cells were predominantly located around the segment in the outer and inner inferior angles, especially in the corner next to the center of the cornea. There were no $\alpha$-SMA positive cells in either control group 1 or control group 2.

Histological findings after ICRS implantation

\section{H-E staining}

The thickness of the epithelium over the segment decreased after surgery. It was significantly thinner than that over the central cornea for all times beyond 4 hours after the surgery (Table 1).

In the stroma around the ICRS during the first 72 hours after implantation, the distance between stromal lamellae increased (Fig. 5a), and this change correlated with the clinically documented edema. When the edema was resolved, there was

Table 1 Epithelial thickness over the central cornea and over the segment during follow-up

\begin{tabular}{lrlll}
\hline $\begin{array}{l}\text { Time after } \\
\text { ICRS } \\
\text { insertion }\end{array}$ & N $\begin{array}{l}\text { Epithelial thickness in } \\
\text { the central cornea }\end{array}$ & $\begin{array}{l}\text { Epithelial thickness } \\
\text { over the segment }\end{array}$ & $p$-value \\
\hline 4 hours & 4 & $29.0 \pm 3.7$ & $22.35 \pm 7.2$ & 0.151 \\
12 hours & 4 & $36.4 \pm 3.6$ & $22.7 \pm 1.6$ & $0.001^{*}$ \\
24 hours & 7 & $31.8 \pm 5.1$ & $23.4 \pm 5.2$ & $0.010^{*}$ \\
48 hours & 6 & $29.8 \pm 5.2$ & $19.7 \pm 3.3$ & $0.003^{*}$ \\
72 hours & 4 & $32.2 \pm 1.6$ & $20.1 \pm 4.9$ & $0.003^{*}$ \\
7 days & 6 & $27.7 \pm 4.7$ & $17.8 \pm 5.2$ & $0.007^{*}$ \\
1 month & 9 & $33.2 \pm 7.2$ & $18.9 \pm 4.5$ & $0.001^{*}$ \\
2 months & 6 & $30.6 \pm 3.0$ & $18.7 \pm 4.1$ & $0.001^{*}$ \\
3 months & 6 & $31.7 \pm 6.2$ & $19 \pm 4.6$ & $0.003^{*}$ \\
4 months & 7 & $35.3 \pm 3.4$ & $23.6 \pm 5.1$ & $0.001^{*}$ \\
6 months & 8 & $32.1 \pm 4.7$ & $19.2 \pm 4.5$ & $0.001^{*}$ \\
\hline
\end{tabular}

ICRS, intrastromal corneal ring segment; M:Mean, SD: Standard deviation. $*$ Differences found statistically significant: $\mathrm{p}<0.05$ compression of the lamellar collagen fibers. In the medium and deep stroma, there was a void where the ICRS was located prior to processing for histological analysis (Fig. $5 \mathrm{a}, \mathrm{b}, \mathrm{c}, \mathrm{d}$ ). This void changed in shape, perimeter (Fig. 6a), and area during the follow-up period. Differences among the perimeter means from one to six months were not statistically significant $(\mathrm{p}>0.05)$.

After ICRS implantation, the location of the segment, represented by the void described above, was equidistant between the epithelium and endothelium, with the base parallel to the endothelium (Figs. 1a and 5a). Then the position of the ICRS changed when the side close to the limbus began to approach the epithelium. The difference between distances D4 and D3 (Fig. 1a) decreased (Fig. 7a) for the first month after insertion. At the same time, the side towards the center of the cornea moved further from the epithelium. The difference between D5 and D3 (Fig. 1a) increased (Fig. 7b) for seven days. The means of the differences between these distances (D5-D3) were not significantly different after seven days $(p>0.05)$, except at three months $(p<0.01)$.

As the corneal edema began to decrease seven days after implantation, cells from the limbus began to approach the segment (Fig. 5e). With time, these cells filled the triangular space left near both inferior angles of the segment (Fig. 5f, g). This area corresponded to the region of lamellar channel deposits seen on clinical examination. The total number of cells in these locations increased until three months (Fig. 5c, f and g) and then decreased at six months (Fig. $5 \mathrm{~d}$ and h, see also Fig. 6b), with new matrix production around them. The number of cells at the limbal side began to increase at 24 hours and continued to do so until 3 months, after which the cell number decreased (Fig. 6b, orange line). The increase in the number of cells around the segment at the side towards the corneal center began later, at three days after implantation, and then, like the cells on the limbal side, continued to increase until three months, and then decreased (Fig. 6b, green line).

The morphology of the stromal cells also changed over time, but it was difficult to differentiate them. At one month, the cells around the inferior edges of the segment were basophilic, had a fusiform shape, and were bigger than keratocytes. Later, at two to four months, the cells became smaller and were more fusiform in shape.

There were no structural changes in Descemet's membrane or the endothelium during the course of the follow-up period.

\section{Transmission electron microscopy (TEM)}

Normal corneas and the areas next to ICRS-implanted corneas were examined by TEM at 1,2, 3, 4, and 6 months after implantation. In the center of the cornea, approximately $1 \mathrm{~mm}$ from the segment, there were no morphologic changes induced by the implanted segment (data not shown). The keratocytes were situated between the lamellae of collagen fibers, and they were oriented parallel to the surface. 

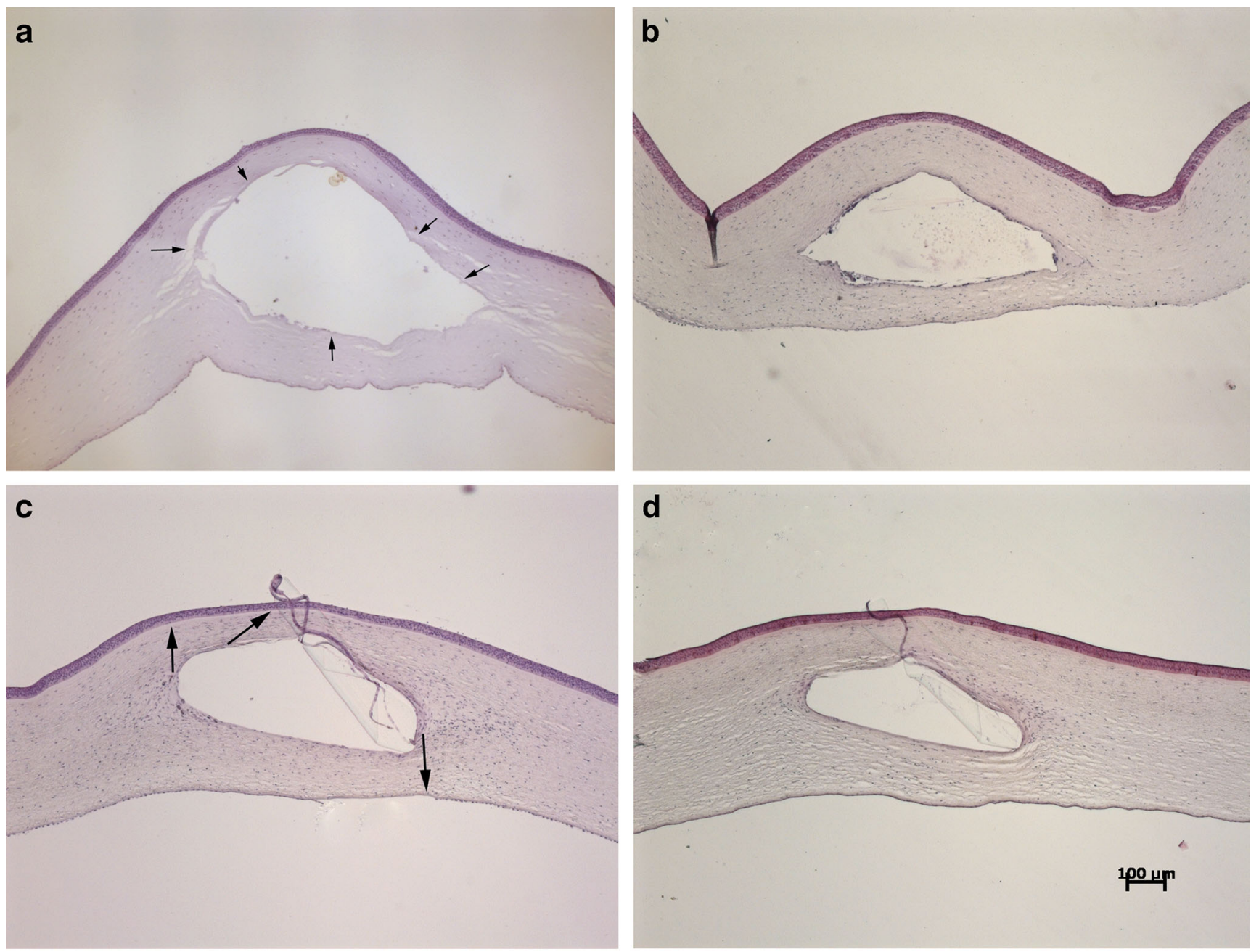
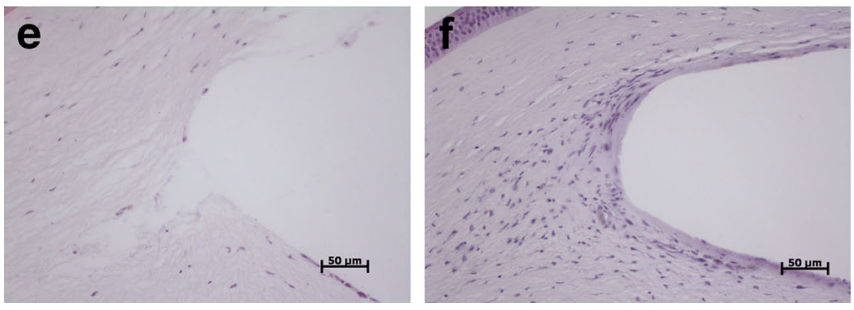

Fig. 5 Cross-section of H-E-stained hen corneas. a, b, c, and d: $5 \times$ magnification showing changes in distances and perimeters: (a) four hours after ICRS implantation; (b) seven days; (c) three months; (d) six months. At four hours, the distance between stromal lamellae increased around the segment (panel a, black arrows). Epithelial hypoplasia is evident in the anterior stroma. Over time, the void left by the segment underwent contraction. The arrangement of cells around the segment and the rotation of the segment in the cornea at different time points are evident. Arrows in

In the area close to the segment, collagen fibrils ran parallel to the implanted segment (Fig. 8a). Layers of fibroblasts were interposed between these new lamellae (Fig. 8b). Outside the tight disposition of stroma around the segment, an area of looser composition was located in the angles that made up the interface with the well-arranged stroma. In this area, fibroblast and myofibroblasts-like cells were present within an irregular deposition of fibers and matrix interruption (Fig. 8c,

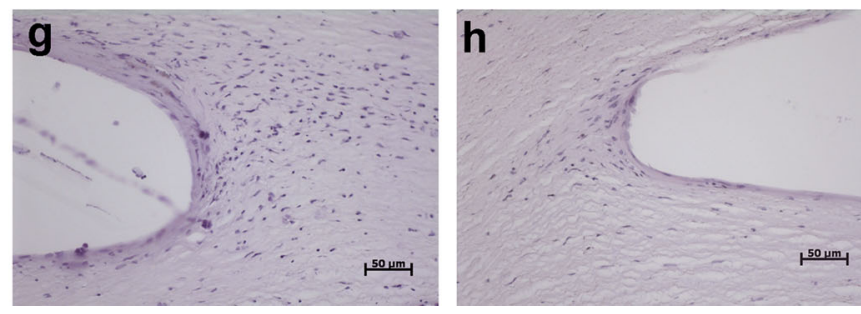

panel $\mathrm{c}$ represent the movement observed during follow-up. $\mathrm{e}, \mathrm{f}, \mathrm{g}$ and $\mathrm{h}$ : $10 \times$ magnification showing changes in cells: (e) At seven days after ICRS insertion, few cells were present at the inferior angle near the limbus. (f, $\mathbf{g}$ ) By three months after insertion, there were large accumulations of cells at the angles near the limbus and near the central cornea respectively. (h) At six months after ICRS insertion, there were fewer cells at the limbal angle with more eosinophilic matrix between the cells

d). Further out from this area, collagen fibrils ran parallel to the corneal surface (Fig. 8e, f) as found in normal corneas.

\section{Discussion}

This study is the widest and most detailed investigation to date into the correlation of the wound healing process after ICRS 
Fig. 6 (a) Change in postimplantation ICRS perimeter. The perimeter of the void left by the ICRS during processing for histology generally became smaller over time and reached an approximate steady state at one month after ICRS insertion (*). (b) Cell counts around the segment during follow-up. Total number of cells surrounding the implanted segments (blue line, Areas $1-4$ in Fig. 1b) increased irregularly until peaking at three months (blue line). Cells at the limbal angle (orange line, Area 3 in Fig. 1b) and at the corneal center angle (green line, Area 4 in Fig. 1b) increased more steadily and then also peaked at three months a

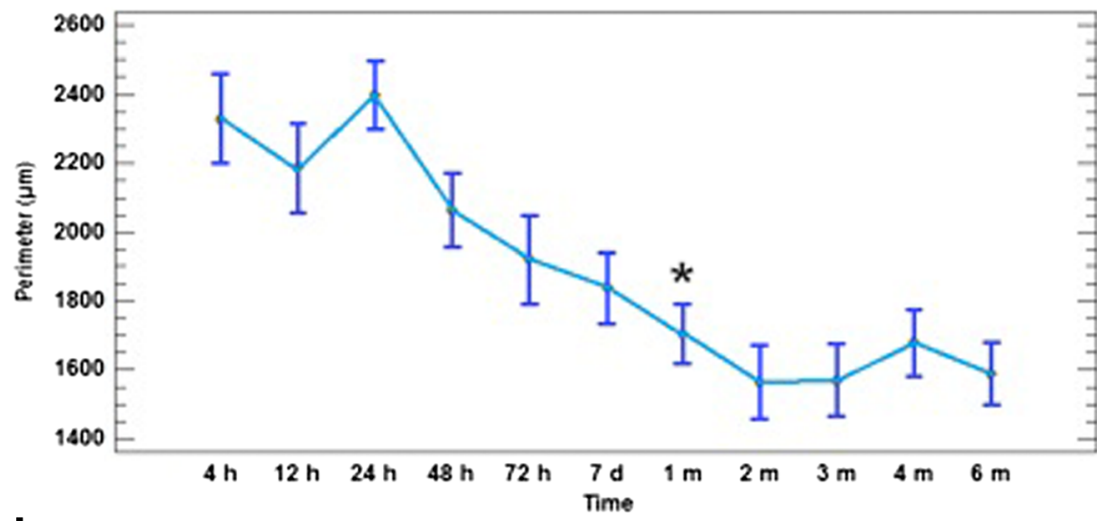

b

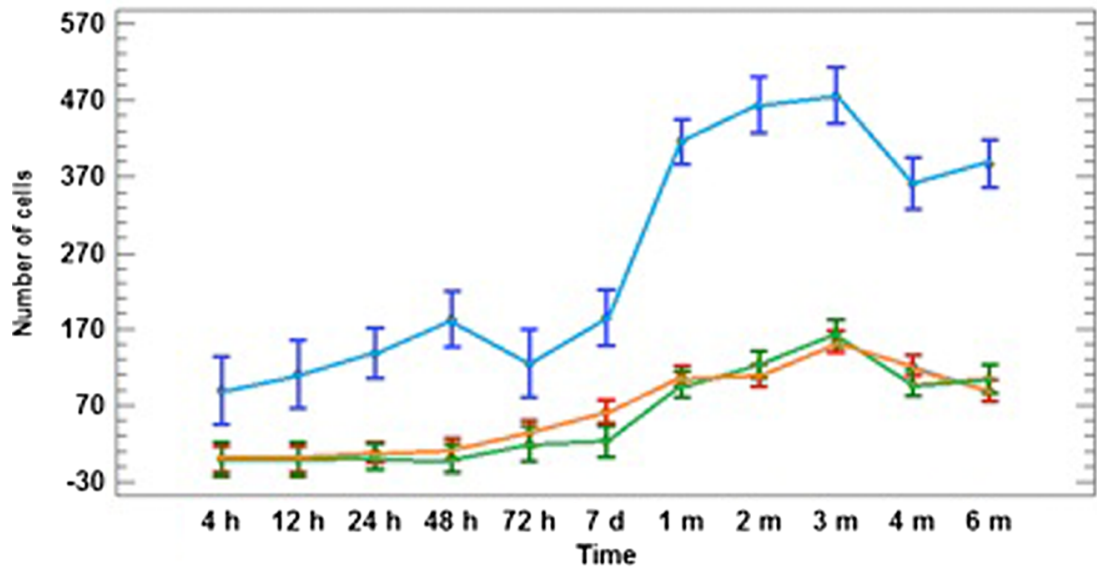

implantation with the clinical events observed in an experimental animal model. Some studies of the refractive and clinical events after ICRS implantation in humans have been carried out by confocal microscopy [11] and anterior segment OCT [12-15]. However, these techniques are not able to describe the cellular events of corneal wound healing around the implanted segments. The histological studies in human corneas were performed on corneas explanted for keratoplasty at different time points, but no temporal sequence of events was established, and the number of eyes analyzed was generally very small [19-21].

Wound healing after ICRS implantation has been studied in different animal models, such as rabbits [17] and hens [22]. In our current study, we used the hen as an animal model because we could adapt the materials of human ICRS implantation to them. The original surgical technique described previously for humans works well in hens, and it has the same learning curve for the investigators (data not shown). Furthermore, the chicken is ethically acceptable, inexpensive, easy to handle, and the corneal anatomy with respect to the number and distribution of layers and the wound healing response is similar to that of humans $[22,23,28,29]$.

After implantation of an ICRS, some events differed from those described with other refractive surgical wounds. For instance, the area of damaged epithelium and basement membrane are smaller than for other surgeries, leading to less release of cytokines [30,31]. Additionally, the extended duration of the implant compared to other corneal surgeries probably caused prolonged biological stress to the surrounding cells.

Stromal and epithelial TUNEL-positive cells were observed as soon as four hours after implantation, similar to that for PRK wound healing $[23,25]$. The peak presence of TUNEL-positive cells was during the first 72 hours after implantation. The number of TUNEL-positive cells after ICRS was also smaller than for PRK $[23,24]$ and LASIK surgery $[24,28]$, probably because of the smaller wound for ICRS implantation. Moreover, a small number of apoptotic cells were present in control group 1 for which the tunnel was made, but no segment was implanted. Thus the initial onset of apoptosis could be due to the damage caused by the surgical procedure, dissection of the intrastromal channel and associated secondary edema, and by release of epithelial cytokines as described after other refractive surgeries [23, 25, 32].

The damaged cells were replaced by new cells labelled with BrdU. The number of epithelial and stromal BrdUpositive cells began to increase at 12 and 24 hours after ICRS implantation, respectively. This was in contrast to some rabbit studies that described Ki-67-positive cells at four hours [25], 

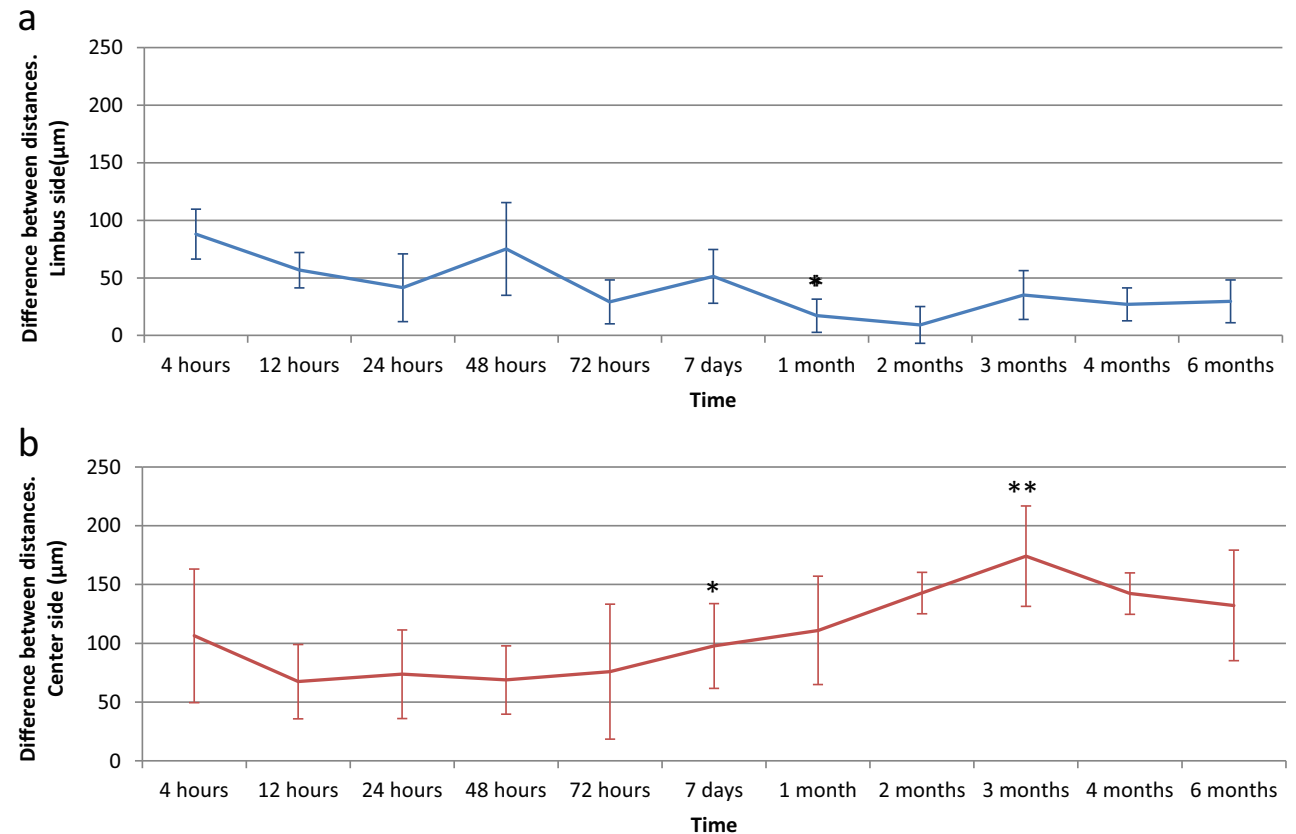

Fig. 7 Differences between means of the distances during follow-up. (a) Changes in the distance from the epithelium to the inferior outer angle of hole left by the segment (D4 in Fig. 1) minus the distance from the epithelium to the superior angle of the triangular hole (D3 in Fig. 1). The differences in these distances decreased from four hours to one month after implantation, when they reached an approximate steady state $(*$ after one month, the differences were not significant). (b) Changes

but in agreement with Netto et al. [33] and Martinez et al. [23] after PRK in rabbits and hens, respectively, and Zieske et al. [34] after epithelial debridement in rabbits.

The proliferation of basal epithelial cells peaked at seven days, later than in previous studies [23, 33, 34]. This could be related to biological stress in this layer caused by the peak of the segment when the edema began to be resolved. Far from the segment, in the central cornea, we also found BrdUpositive cells. This finding could be due to stress caused by the segment as it produced flattening of the central cornea.

For stromal cells, the onset of proliferation was similar to that for PRK in hens [23] and PRK and LASIK surgery in rabbits [25]. The peak occurred at 72 hours after surgery and decreased from 7 days until the end of the study. Most of the BrdU-labeled cells were associated with the limbus, which could indicate specific activation of the limbal cells. The number of cells in the center of the corneal stroma is noteworthy, probably arriving there by migration from the limbus. This event has not been described previously, but it is also in agreement with the existence of mesenchymal stem cells in the limbus $[35,36]$.

Some of the signals released after ICRS implantation may have origins other than the epithelium, such as activated keratocytes (autocrine control) and the mechanical strain placed on the collagen fibers. This was supported by the fact that in the corneas of control group 1, where we made the channel without implanting the segment, in the distance from the epithelium to the inferior inner angle of the hole left by the segment (D5 in Fig. 1) minus the distance from the epithelium to the superior angle of the triangular hole (D3 in Fig. 1). The differences in these distances increased from four hours to seven days when the differences became no longer statistically significant $(*)$, except at three months $(* *)$

we did not observe stromal proliferation and wound repair after two days.

Many studies have been conducted to identify the molecular mechanisms that control the differentiation of myofibroblasts from fibroblasts [25, 37, 38]. According to these studies, the disruption of the epithelial basement membrane correlates with the differentiation of myofibroblasts due to the release of transforming growth factor beta-1 [31] followed by myofibroblast-expressed SMA. Although the damage caused to the basement membrane in the incision for ICRS implantation is small, we also found $\propto-$ SMA-positive cells around the segment, although there were fewer than after other procedures, such as phototherapeutic keratectomy [32] and PRK [39]. These cells were $\alpha$-SMA-positive from one month to three months, which correlated with the appearance of haze around the segment, as reported in other studies $[23,40,41]$. The $\propto-$ SMA-positive cells were located next to the segment, in the inferior angle towards the center of the cornea. This could be associated with the rotational movement by the segment during the first three months after implantation and with the contraction of the perimeter around the segment.

We found an increase in stromal cells from four hours to one month after ICRS implantation. This was followed by a plateau until the third month and then a decrease between the fourth and sixth months. The largest number of stromal cells was always next to both angles of the ICRS compared to the number of cells over and under the segment. This supports our 

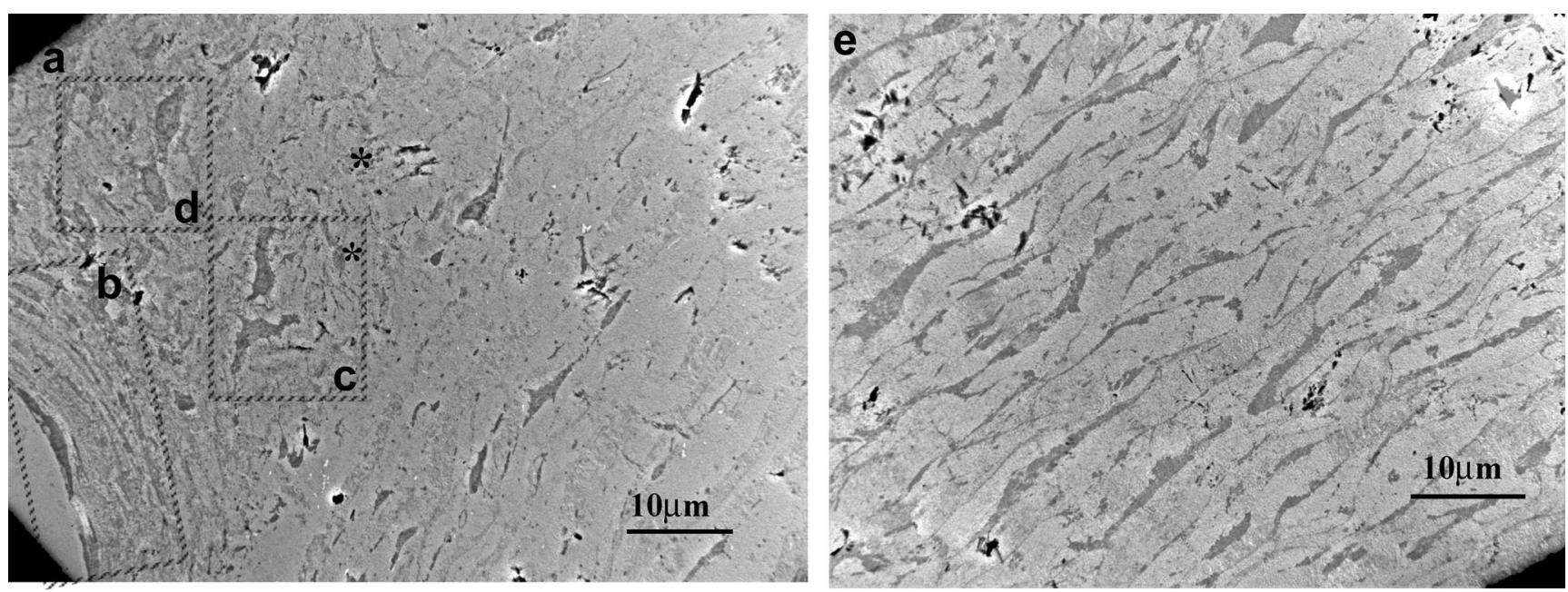
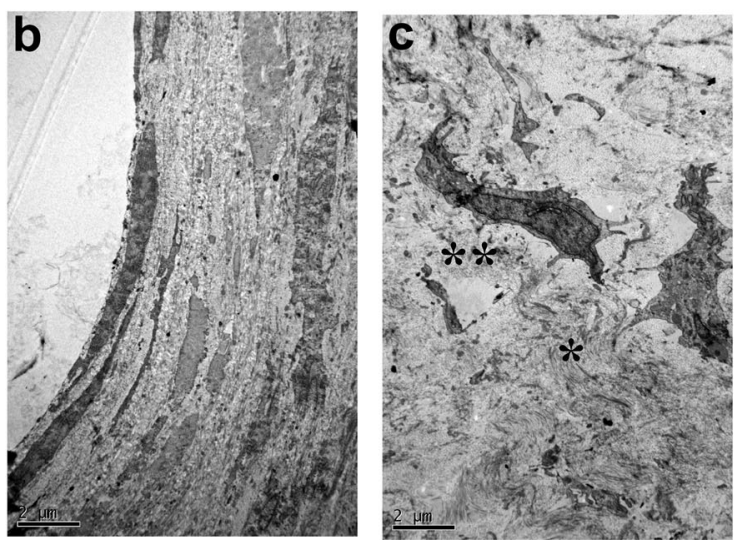

Fig. 8 Electron microscopy of hen corneas in areas around the segment. (a) New arrangement of extracellular matrix and fibroblasts around the segment. (b) Fibroblast and collagen were tightly apposed to the segment. (c) Further from the ICRS, the fibroblasts and collagen fibrils were disorganized. (d) Interruptions of the extracellular matrix $(*)$ were likely

hypothesis of limbal cell activation, possibly due to the segment causing biological stress. The peak in this curve was at 1 month, which contrasted with the peak proliferation of stromal cells at 72 hours. This difference could indicate that the cause of the large number of cells found at one, two and three months was not only related to the proliferation measured one hour after BrdU injection, but was also due to the sum of proliferation and migration during the entire month. These cells were fibroblast- and myofibroblast-like as indicated by TEM and $\alpha$-SMA staining. We did not find inflammatory cells, though they have been described in a recent study and characterized as macrophages [21].

The rotation of the segment may be described as a movement in which the inferior angle next to the limbus approached the epithelium and the other inferior angle next to the center increased in distance from the epithelium, with no change in the distance from the epithelium to the peak of the segment. These events stabilized at approximately one month and were correlated with the peak number of cells around the segment and with the increased quantity of clinical deposits. At three months, there was an additional increase in the difference between the distance from the epithelium to the inner angle (center side) of the hole left by the segment (D5 in Fig. 1a) minus the distance from the epithelium to the peak of the triangular hole (D3 in Fig. 1a). These changes might indicate an additional movement caused by myofibroblasts rather than an increase in the number of cells. Similar movements were previously described in two studies with OCT in humans $[13,15]$. Other studies also conducted in humans have reported that the depth of the segment, i.e., the distance from the epithelium to the base of the segment, decreased with increasing distance from the incision site, especially after manual dissection, because the inferior cornea is weaker and more flexible $[12,14]$.

While different explanations have been given for the clinically-observed "deposits," the bulk of the deposits are related to the appearance of new matrix material and the deposition of cells. We think that the interface between the new and old matrix and the unorganized position of cells produce changes in the refractive index and loss of transparency. These 
changes are inappropriately referred to as "deposits" by the clinical appearance.

Our hen model for ICRS implantation has some drawbacks. First, the corneal measurements were not exactly the same as those in humans; so, for this reason, we had to create and adapt the surgical instruments to our animal model. Second, there are differences in the collagen arrangement [42] and accommodation mechanism [43,44], although we believe that these did not interfere with the wound healing process. Future studies will be performed to examine the tissue reactions measured as changes in mRNA and protein expression to better understand this specific wound healing response.

Our experiments were performed in normal hen corneas; however, the tissue reaction in pathologic human corneas, e.g., ones with ectatic disease, could be somewhat different. We think that wound healing in normal tissues rather than pathologic ones is the first step to better understanding the wound response mechanism because there are fewer factors that could influence the response. In ectatic eyes, the implants must be well-tolerated with minimal inflammation, and they should provide improved refractive correction as they do in our model. Further, the "deposits" reported by others are not necessarily complications of the wound healing response. Rather if the deposits are areas containing new cells and active matrix production around the implants, they could actually reinforce the existing stroma of the diseased corneas.

In conclusion, an experimental animal model of ICRS implantation in hens was developed and characterized by clinical and biological observations. We described the complete wound healing process after ICRS implantation and established the relationship between the clinical and cellular events that both seem to stabilize at one month. The wound healing process had some specific events related to the small size of the damage to the epithelium and basement membrane and to the ICRS permanently implanted inside the cornea. We believe these events caused continuous stress on the cells and the extracellular matrix, unlike healing following PRK and LASIK surgery. We also identified movement of the segment inside the corneal stroma and suggested reasons that it occurred. Finally, we identified the clinical "deposits" as activated cells and a new, unorganized extracellular matrix.

Acknowledgments The authors would like to thank Doctor Angel García Barcia, Félix Gómez, and Juanjo Arribas for animal care support. Ferrara Rings and AJL Ophthalmics provided both PMMA segments and surgical instruments. Luis Santiago provided electron microscopy technical assistance. The authors also would like to thank Doctor José Alfonso for his contribution as scientific advisor during the last portions of this study. We also thank Carmina Sanchis, Raquel Llopis, and Laura López for methodological support.

Conflict of interest The authors have no commercial relationship with any of the materials mentioned in the article.

\section{References}

1. Romero-Jimenez M, Santodomingo-Rubido J, Wolffsohn JS (2010) Keratoconus: a review. Cont Lens Anterior Eye 33(4):157-166. doi: 10.1016/j.clae.2010.04.006, quiz 205

2. Rabinowitz YS (1998) Keratoconus. Surv Ophthalmol 42(4):297319

3. Olson RJ, Pingree M, Ridges R, Lundergan ML, Alldredge C Jr, Clinch TE (2000) Penetrating keratoplasty for keratoconus: a longterm review of results and complications. J Cataract Refract Surg 26(7):987-991

4. Wollensak G, Spoerl E, Seiler T (2003) Riboflavin/ultraviolet-a-induced collagen crosslinking for the treatment of keratoconus. Am J Ophthalmol 135(5):620-627

5. Pinero DP, Alio JL (2010) Intracorneal ring segments in ectatic corneal disease - a review. Clin Experiment Ophthalmol 38(2):154-167. doi:10.1111/j.1442-9071.2010.02197.x

6. Schanzlin DJ, Asbell PA, Burris TE, Durrie DS (1997) The intrastromal corneal ring segments. Phase II results for the correction of myopia. Ophthalmology 104(7):1067-1078

7. Schanzlin DJ, Abbott RL, Asbell PA, Assil KK, Burris TE, Durrie DS, Fouraker BD, Lindstrom RL, McDonald JE 2nd, Verity SM, Waring GO 3rd (2001) Two-year outcomes of intrastromal corneal ring segments for the correction of myopia. Ophthalmology 108(9): $1688-1694$

8. Kymionis GD, Grentzelos MA, Diakonis VF, Pallikaris AI, Pallikaris IG (2009) Nine-year follow-up of intacs implantation for keratoconus. Open Ophthalmol J 3:77-81. doi:10.2174/ 1874364100903010077

9. Ferrara G, Torquetti L, Ferrara P, Merayo-Lloves J (2012) Intrastromal corneal ring segments: visual outcomes from a large case series. Clin Experiment Ophthalmol 40(5):433-439. doi:10. 1111/j.1442-9071.2011.02698.x

10. Asbell PA, Ucakhan OO, Abbott RL, Assil KA, Burris TE, Durrie DS, Lindstrom RL, Schanzlin DJ, Verity SM, Waring GO 3rd (2001) Intrastomal corneal ring segments: reversibility of refractive effect. J Refract Surg 17(1):25-31

11. Ruckhofer J, Bohnke M, Alzner E, Grabner G (2000) Confocal microscopy after implantation of intrastromal corneal ring segments. Ophthalmology 107(12):2144-2151

12. Ortiz S, Perez-Merino P, Alejandre N, Gambra E, Jimenez-Alfaro I, Marcos S (2012) Quantitative OCT-based corneal topography in keratoconus with intracorneal ring segments. Biomed Opt Express 3(5):814-824. doi:10.1364/BOE.3.000814

13. Perez-Merino P, Ortiz S, Alejandre N, Jimenez-Alfaro I, Marcos S (2013) Quantitative OCT-based Longitudinal Evaluation of Intracorneal Ring Segment Implantation in Keratoconus. Invest Ophthalmol Vis Sci 54(9):6040-6051. doi:10.1167/iovs.13-12401

14. Lai MM, Tang M, Andrade EM, Li Y, Khurana RN, Song JC, Huang D (2006) Optical coherence tomography to assess intrastromal corneal ring segment depth in keratoconic eyes. J Cataract Refract Surg 32(11):1860-1865. doi:10.1016/j.jcrs.2006.05.030

15. Gorgun E, Kucumen RB, Yenerel NM, Ciftci F (2012) Assessment of intrastromal corneal ring segment position with anterior segment optical coherence tomography. Ophthalmic Surg Lasers Imaging 43(3): 214-221. doi:10.3928/15428877-20120301-01

16. Ferrer C, Alio JL, Montanes AU, Perez-Santonja JJ, del Rio MA, de Toledo JA, Teus MA, Javaloy J (2010) Causes of intrastromal corneal ring segment explantation: clinicopathologic correlation analysis. J Cataract Refract Surg 36(6):970-977. doi:10.1016/j.jcrs.2009.12.042

17. Twa MD, Ruckhofer J, Kash RL, Costello M, Schanzlin DJ (2003) Histologic evaluation of corneal stroma in rabbits after intrastromal corneal ring implantation. Cornea 22(2):146-152 
18. Ruckhofer J, Twa MD, Schanzlin DJ (2000) Clinical characteristics of lamellar channel deposits after implantation of intacs. J Cataract Refract Surg 26(10):1473-1479

19. Samimi S, Leger F, Touboul D, Colin J (2007) Histopathological findings after intracorneal ring segment implantation in keratoconic human corneas. J Cataract Refract Surg 33(2):247-253. doi:10.1016/ j.jcrs.2006.08.059

20. Maguen E, Rabinowitz YS, Regev L, Saghizadeh M, Sasaki T, Ljubimov AV (2008) Alterations of extracellular matrix components and proteinases in human corneal buttons with INTACS for postlaser in situ keratomileusis keratectasia and keratoconus. Cornea 27(5):565-573. doi:10.1097/ICO.0b013e318165b1cd

21. Cao X, Ursea R, Shen D, Ramkumar HL, Chan CC (2011) Hypocellular scar formation or aberrant fibrosis induced by an intrastromal corneal ring: a case report. J Med Case Rep 5:398. doi:10.1186/1752-1947-5-398

22. Merayo-Lloves J, Blanco-Mezquita T, Ibares-Frias L, Fabiani L, Alvarez-Barcia A, Martinez-Garcia C (2010) Induction of controlled wound healing with PMMA segments in the deep stroma in corneas of hens. Eur J Ophthalmol 20(1):62-70

23. Martinez-Garcia MC, Merayo-Lloves J, Blanco-Mezquita T, MarSardana S (2006) Wound healing following refractive surgery in hens. Exp Eye Res 83(4):728-735. doi:10.1016/j.exer.2006.02.017

24. Wilson SE (2002) Analysis of the keratocyte apoptosis, keratocyte proliferation, and myofibroblast transformation responses after photorefractive keratectomy and laser in situ keratomileusis. Trans Am Ophthalmol Soc 100:411-433

25. Mohan RR, Hutcheon AE, Choi R, Hong J, Lee J, Ambrosio R Jr, Zieske JD, Wilson SE (2003) Apoptosis, necrosis, proliferation, and myofibroblast generation in the stroma following LASIK and PRK. Exp Eye Res 76(1):71-87

26. Efron N, Morgan PB, Katsara SS (2001) Validation of grading scales for contact lens complications. Ophthalmic Physiol Opt 21(1):17-29

27. Fantes FE, Hanna KD, Waring GO 3rd, Pouliquen Y, Thompson KP, Savoldelli M (1990) Wound healing after excimer laser keratomileusis (photorefractive keratectomy) in monkeys. Arch Ophthalmol 108(5):665-675

28. Torres RM, Merayo-Lloves J, Blanco-Mezquita JT, Gunther CP, Rodriguez G, Gutierez R, Martinez-Garcia C (2005) Experimental model of laser in situ keratomileusis in hens. J Refract Surg 21(4): 392-398

29. Fowler WC, Chang DH, Roberts BC, Zarovnaya EL, Proia AD (2004) A new paradigm for corneal wound healing research: the white leghorn chicken (Gallus gallus domesticus). Curr Eye Res 28(4):241-250

30. Torricelli AA, Singh V, Santhiago MR, Wilson SE (2013) The corneal epithelial basement membrane: structure, function, and disease.
Invest Ophthalmol Vis Sci 54(9):6390-6400. doi:10.1167/iovs. 1312547

31. Torricelli AA, Singh V, Agrawal V, Santhiago MR, Wilson SE (2013) Transmission electron microscopy analysis of epithelial basement membrane repair in rabbit corneas with haze. Invest Ophthalmol Vis Sci 54(6):4026-4033. doi:10.1167/iovs. 13-12106

32. Wilson SE, Liu JJ, Mohan RR (1999) Stromal-epithelial interactions in the cornea. Prog Retin Eye Res 18(3):293-309

33. Netto MV, Mohan RR, Ambrosio R Jr, Hutcheon AE, Zieske JD, Wilson SE (2005) Wound healing in the cornea: a review of refractive surgery complications and new prospects for therapy. Cornea 24(5): $509-522$

34. Zieske JD (2001) Extracellular matrix and wound healing. Curr Opin Ophthalmol 12(4):237-241

35. Polisetty N, Fatima A, Madhira SL, Sangwan VS, Vemuganti GK (2008) Mesenchymal cells from limbal stroma of human eye. Mol Vis $14: 431-442$

36. Du Y, Funderburgh ML, Mann MM, SundarRaj N, Funderburgh JL (2005) Multipotent stem cells in human corneal stroma. Stem Cells 23(9):1266-1275. doi:10.1634/stemcells.2004-0256

37. Stramer BM, Zieske JD, Jung JC, Austin JS, Fini ME (2003) Molecular mechanisms controlling the fibrotic repair phenotype in cornea: implications for surgical outcomes. Invest Ophthalmol Vis Sci 44(10):4237-4246

38. Miyamoto T, Saika S, Yamanaka A, Kawashima Y, Suzuki Y, Ohnishi Y (2003) Wound healing in rabbit corneas after photorefractive keratectomy and laser in situ keratomileusis. J Cataract Refract Surg 29(1):153-158

39. Netto MV, Mohan RR, Sinha S, Sharma A, Dupps W, Wilson SE (2006) Stromal haze, myofibroblasts, and surface irregularity after PRK. Exp Eye Res 82(5):788-797. doi:10.1016/j.exer.2005.09.021

40. Kamburoglu G, Ertan A, Saracbasi O (2009) Measurement of depth of Intacs implanted via femtosecond laser using Pentacam. J Refract Surg 25(4):377-382

41. Gibson DJ, Tuli SS, Schultz GS (2013) The progression of haze formation in rabbit corneas following phototherapeutic keratectomy. Invest Ophthalmol Vis Sci 54(7):4776-4781. doi:10.1167/iovs. 1311976

42. Boote C, Hayes S, Jones S, Quantock AJ, Hocking PM, Inglehearn CF, Ali M, Meek KM (2008) Collagen organization in the chicken cornea and structural alterations in the retinopathy, globe enlarged (rge) phenotype-an X-ray diffraction study. J Struct Biol 161(1):18. doi:10.1016/j.jsb.2007.08.015

43. Schaeffel F, Glasser A, Howland HC (1988) Accommodation, refractive error and eye growth in chickens. Vis Res 28(5):639-657

44. Schaeffel F, Howland HC (1987) Corneal accommodation in chick and pigeon. J Comp Physiol A 160(3):375-384 